\title{
Transition Discourse, Food, and Computing within Limits
}

\author{
David G. Hendry \\ dhendry@uw.edu \\ Value Sensitive Design Lab \\ The Information School, University of Washington \\ Seattle, Washington, USA
}

\begin{abstract}
The LIMITs workshop series is a transition system, which shapes the work of activists, educators, and researchers. It does so, in part, by the development of language and tools and by catalyzing conversations about reality and possible futures. Given this proposition and drawing on ontologically oriented analysis and design, I explore the transition discourse of eight LIMITs' papers, which consider aspects of food. The papers represent competing views of the future of place and planet. Building on this review, I discuss worldviews and transitions, transitions and time, and I explore how formative and instrumental approaches in computing research can contribute to institutional and cultural adaptation.
\end{abstract}

\section{INTRODUCTION}

LIMITs offers a background of tools, language, and conversations for considering our planetary predicament of climate change, survival, and justice. Accordingly, I think that LIMITs itself-generally, as a community and socio-technical system, and more particularly, as a body of discourse-is a transition system. In other words:

[LIMITs engages in a] transformative shift in computing research and practice to one that would use computing to contribute to the overall process of transitioning to a future in which the well-being of humans and other species is the primary objective [43, p. 87]

By considering the systemic dimensions of socio-technical systems taken up by LIMITS, I seek to show something of how LIMITS conceptualizes transitions and futures. I focus, specifically, on sociotechnical systems related to food.

According to Arturo Escobar [12, chap. 4], transition design is a form of ontological design, which, simply put, creates the conditions for desired ways of being and acting. To develop his characterization of ontological design, which I discuss in detail below, Escobar builds, in part, on Winograd and Flores [76], citing the profound insight: "We encounter the deep questions of design when we recognize that in designing tools we are designing ways of being (Winograd and Flores, 1986, xi)" [12, p. 110]. One implication is that even when we doggedly try to transcend our current context, its shaping influence on our reality is unavoidable. A second is that the design of tools, and their everyday adaptive use, catalyzes conversations, which, in turn, shape the future.

What kind of tool is LIMITs? While many productive answers could be formulated, I propose that LIMITs is an information system of discourse about transitions. As a body of discourse, it shapes people who read and synthesize. Those people might, in turn, shape systems through a multiplicity of conversations and actions. About this dynamic shaping, Kaczmarek et al. write, "the many tendrils of our scholarship - project narratives, student mentoring, contribution articulations... - have implications for collective futures far beyond the LIMITs community"[33, p. 246].

To our collective futures, our survival seems to depend on good ideas and systems that enable reason to prevail across scales. Yet, folly seems to be an enduring human disposition, even when there is no time to dilly dally, as Greta Thunberg regularly reminds world leaders [21]. The social sciences, in an optimistic vein, are learning more about irrationality, including climate denial [47]; how uncritical affiliation to ideologies can be resisted; and the pernicious effects of biases and how they can be checked [55].

That said, science, technology and reason are not likely to be enough. One obstacle, no doubt, is to re-imagine dwelling on Earth, ways of being and acting that are sustainable and that promote human flourishing and dignity [50]. While seemingly theoretical, this framing can be entirely practical, leading to the adaption of our institutions and built environments, and, indeed, to the re-design of ourselves [19]. Taking action, however, does seem to rely on technical and moral imaginations, along with our collective will.

According to Escobar, "transitions are not designed but are emergent; they depend on the mix of interacting dynamic processes" [12, p. 152]. Thus, Escobar emphasizes the importance of the shaping influence of "transition discourses." It is for this reason that ontological analysis and design seems essential to the goals of LIMITs.

\section{ON EARTH: A PERSONAL FOOTING}

As a demonstration of ontological reflection, I reveal a little about my situatedness on Earth; then, I turn to background.

One of my earliest memories is a fishing story, when at the age of three I watched a fisherman land a large channel catfish on the shores of the Saint Lawrence River, the traditional home of the Iroquoians. Once on the pink granite rock of the Canadian Shield, I was scared by the fish's long whiskers and bloodied gills. Somehow I knew that its proper place was in the river, not on the rocks gulping for oxygen and dying. I grieved for the fish.

Because of my familial history and cultural environment, I hold many such stories; they have partially designed me.

The question of Nature-of the Ontario "bush," wildness, wilderness, pristineness, land, landscape, and shoreline-has long interested me. For now, I've settled on the word "outdoors," believing that passing or routine experiences under the sky can be restorative [24]. In this vein, Henry David Thoreau gives insight for seeing and telling of the world, vividly recognized in the contemporary photographs by Chanell Stone [40, 63]:

It is in vain to dream of a wildness distant from ourselves. There is none such. It is the bog in our brains and bowls, the primitive vigor of Nature in us, that 
inspires that dream. I shall never find in the wilds of Labrador any greater wildness than in some recess of Concord, i.e. than I import into it.

Henry David Thoreau, Journal, August 30, $1856^{1}$

Beginning with land, Aldo Leopold asks that individuals break out of a human v. non-human dualism and invites a biocentric worldview [58]. He wrote in 1949: "a land ethic changes the role of Homo sapiens from conqueror of the land-community [soils, waters, plants, and animals] to plain member and citizen of it. It implies respect for his fellow-members, and also respect for the community as such" [35, p. 240]. Today, to the list of fellow-members I might add clean air and the continued possibility for blue-sky days and starry nights. Following Leopold and others [e.g., 6, 38, 73], I believe that much of Western society needs to re-design its relationship to Earth. Robin Wall Kimmerer, a member of the Citizen Potawatomi Nation, writes: "It's not the land that is broken, but more importantly, our relationship to the land.... our relationship with the land cannot heal until we hear its stories. But who will tell them?" [34, p. 9].

On reflection, I believe that the transition from the Industrial cum Information Age to a new Age will require many land ethics, which will vary across individuals, societies, and eras. This transition is happening now by the efforts of more than a million organizations [26], LIMITs being one example, which gives me optimism. That said, the Keeling Curve [45] looms darkly. When my grandfather was three, in 1901, the planet's $\mathrm{CO}_{2}$ atmospheric concentration was about $296 \mathrm{ppm}$. When I was three, about $320 \mathrm{ppm}$. Now, the reading is about $415 \mathrm{ppm}$, and global warming in excess of 3 ${ }^{\circ} \mathrm{C}$ by 2100 seems likely [56]. While I can examine the curve's numbers, I don't know how to genuinely place its troubling trajectory into my stories of the outdoors. Sadly, I ask: Is an "asteroid hitting the Earth in slow motion" [32, p. 43]? Yes, so the numbers indicate, and by being alive, I'm partly responsible.

\section{ONTOLOGICAL DESIGN}

Working definition: Ontological Design is the placement of tools, language, and conversation into a context so as to create the conditions for being and acting, which allows for a new, desired reality to emerge.

In this background section, I discuss Escobar's characterization of ontological design [12], which is complex and not easily distilled. His characterization draws substantially on Winograd and Flores' theory of design and interactive computing [76] and Maturana and Varela's biological account of cognition and theory of mind [41]. It also draws on Fry's philosophical thought, especially the concept of defuturing [19], along with other critical design scholars. The scholarly network of influence is notable: Maturana and Verela [41] is also a foundational piece for Winograd and Flores [76] while Heideggerian phenomenology is a foundation piece for both Winograd and Flores [76] and Fry [19]. Also, Escobar seeks to break out of dualisms (e.g., human beings v. nature), a central goal of Heidegger [see 28], whom he cites. Finally, Escobar draws on critical thinkers, designers, and activists from the Global South, largely South and Central America, and the Global North.

\footnotetext{
${ }^{1}$ I first encountered this quotation as an epigraph in a book by Simon Schama [59]
}

To clarify the working definition given above, consider Winston Churchill's oft-cited quotation, delivered in a speech in the British House of Commons in 1943:

We shape our buildings and afterwards our buildings shape us.

This was no idle reflection. Rather, I interpret it as a deep appeal to intentional design, for Churchill was arguing for the future of the British parliamentary system of government.

Consider the dire context, revealed in the text of his speech [27]. Two years earlier, the House of Commons was destroyed by a bombing raid during the last days of the Blitz. To preserve the parliamentary system, Churchill sought to preserve traditional political debate and civility. To do that, he wanted to maintain the status quo, where the majority party and the opposition directly face each other across the floor. Thus the importance of the building's design: He wanted the traditional oblong form to be restored, not a new semi-circular design, as some political theorists of the day recommended. In summary, the restoration of tradition, which was at least partly destroyed in war, was designed through these elements: tools (House of Commons building); culture, practices, and values (debate format and civility); and, language and metaphor (Churchill's shaping metaphor anchors his argument).

I now unpack Esobar's theorizing of ontological design by proposing these descriptive dimensions, which should be readily recognizable within the Churchill case (speech and context):

- Shaping influence. Tools and language, in nested and networked patterns, dynamically shape being and action.

- Processional structure. The shaping influences are processional, drawing on historical circumstances, picking up new tools and language, and creating visions for possible futures.

- Emergence. The shaping influences and processional structures lead to non-local phenomena. Change is emergent, by a multiplicity of actions.

- Conditions of existence. Tools and language, in moment-tomoment experiences, constitute an individual's reality.

- Design elements. A design situation comprises humans and non-human living organisms, materials of all qualities, values, spirits, sacred places, and so on.

- Designers. We are all designers. We design each other by our conversations, our tools, and our adaptive use of tools.

- Intervention. An individual or group intervenes, seeking an intentional change to reality.

- Systemic change. Aimed at systemic change, interventions are holistic and catalytic.

Escobar situates ontological design in critical design studies and among design thinkers who strive for truly radical socio-political change. Overturning capitalism and other hegemonic structures is one of his main concerns. Accordingly, his characterization of ontological design is prescriptive; whereas, the distillation just presented in the bullet points is descriptive, for it strips away his critical, interventionist stance. Indeed, the Churchill case-also my personal reflections-illustrate a key point: The purpose of ontological design can be directed to building Nazi Germany, restoring the past, maintaining business-as-usual, or anything else. 


\section{TRANSITION DISCOURSE}

Working definition: Transition Discourses imagine and represent new Ages, which are radically different from the current Age.

The Convivial Age; The Degrowth Age; The Sustainment AgeWhat Age ought civilization design for itself?

Escobar answers with "A world where many worlds fit" [12, p. $\mathrm{xvi}$, that is, the pluriverse, where no one world can destroy another or lead to de-futuring [19], that is, to the destruction of possible futures through unsustainable practices; and where autonomy within a world and difference among worlds is valued. On inventing worlds, he writes that transition narratives from "multiple sites of academic and activist life over the past decade is one of the most anticipatory signs of our times" [12, p. 139].

Transition discourse refers to a conceptualization of a world that ought to be created whereas transition design is concerned with the processes for getting there. Both are forms of ontological design. Transition discourses are rooted in the past and present; the future comes from those roots. Joanna Macy and Chris Johnstone, for example, refer to three stories, Business as Usual, the Great Unravelling, and the Great Turning [38]. About the Great Turning:

... it is the essential adventure of our times. It involves the transition from a doomed economy of the industrial growth to a life-sustaining society committed to the recovery of our world.... Social and technical innovations converge, mobilizing people's energy, attention, creativity, and determination... [p. 27]

Escobar reviews several such discourses and related work, developing a normative position; namely, in my interpretation, transition discourse ought to promote: (1) The values of compassion and care; (2) The reconnection of humans to Earth; (3) Relationality among human and non-human beings; (4) Tools and technologies that lead to convivial and communal worlds; and (5) Autonomy of worlds and respect for difference among worlds.

This basic summary of a complex body of thought illustrates how the descriptive dimensions from the previous section might be filled in with normative prescriptions for shaping the future, such as "Individuals in the future ought (or ought not)..., "Future institutions should (or should not)...," and so on. Similarly, we might invent claims for the present, such as: "Today, individuals should...." This latter approach, focused on actions in the current moment, is followed by the Great Turning; thus, it avoids the need to foresee the future in detail, a difficult or impossible task even with methods for creative and insightful envisioning [11, 65].

While a designer might add nuance and priorities to prescriptions (e.g., "It would be good if..."), the distinction between a description of an ontological process and normative prescriptions, which are laden with ethical values, should be clear. Relatedly, this distinction makes ethical and moral questions apparent. For example, regarding the design elements dimension, Esobar leans to a biocentric view. But, without discussing the matter here, it might be possible that, at least in some worlds, an anthropocentric position is the better one. Second, within the intervention dimension are found difficult questions related to the designer's purpose and to the engagement of such values as community autonomy, duty of care, power, responsibility, and service relationships.

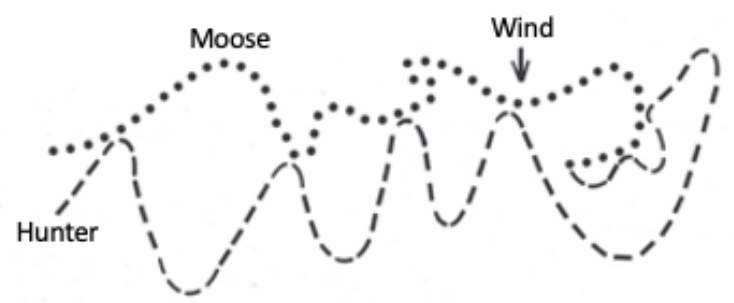

Figure 1: Method for tracking a moose. Credit: Richard K. Nelson [46, p. 42]. Cropped and labels redrawn.

\section{WORKING SCENARIOS}

In this section, I present three working scenarios, which illustrate ontological analysis and design while also revealing tensions and difficulties related to intervention.

Scenario 1: The moose hunter. The Ts'ibaa Laałta Hut'aana ${ }^{2}$ hold ancient knowledge for hunting animals, including moose. In Figure 1 , starting from the left, the moose and hunter are moving in the same general direction, with the hunter some ways behind. With your finger, trace the moose's trail, then repeat for the trail followed by the hunter. What is going on?

[the] moose will often circle downwind of their own tracks before lying down to rest; this way they will catch the scent of any animal that might be following their trail. To avoid detection by the animal, a hunter makes looping detours downwind away from the moose's trail, returning to it at intervals. When he finally circles back and finds no tracks, he knows that the animal has doubled back. So now he makes several small loops... [46, p. 43].

While much could be considered, I would like to briefly foreground three points. First, the moose and the hunter are structurally coupled $[12,41]$; that is, the moose's actual and imagined behavior shapes the behavior of the hunter, along with many other features in the environment (e.g., time of day, quality of the snow, etc.). The moose and hunter, in other words, are in a relational experience. Second, the hunter's understanding of reality emerges momentto-moment as he moves and encounters, or does not encounter, signs of the moose. Third, we can imagine enormous skill related to tool use and ecological discernment, beginning, for example, with knowing how to keep one's toes warm in the cold.

Stepping back, a key consideration is the intergenerational exchange of hunting know-how. We can imagine young people being designed through experiences shared with other hunters and elders, and by listening to and telling hunting stories, oral skills learned in relationship with others [64]. It is also the case that enforcing government policy on sustainable hunting or land use, even if informed by ecological science, will perturb, or destroy, ancient knowledge and harm, or break, relational ways of being [68].

Scenario 2: The bus commuter. A university commuter is in the midst of deciding how to get home (Figure 2). Unexpectedly, it is raining. Accordingly, they have decided not to cycle home, but to

\footnotetext{
${ }^{2}$ Koyukon translation: "people among the tall standing spruce trees" [46, preface]. The Koyukon are Indigenous Peoples who have lived in Alaska for time immemorial.
} 


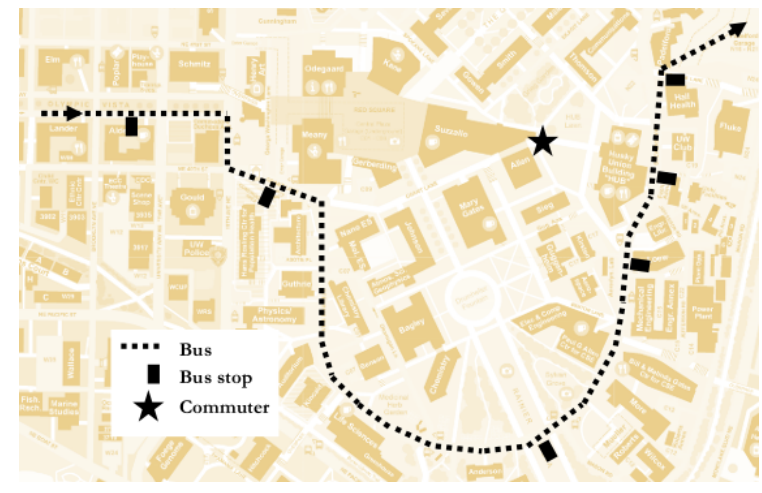

Figure 2: Sketch of commuter tracking a bus on a university campus. Credit: Map from University of Washington [69].

take the bus. They open a transportation app, which provides information for when to expect the bus, but the app does not answer two crucial questions: (1) Will an open spot on the bus's bicycle rack be available? and (2) Will a seat be available (they do not want to stand)? They decide to walk their bicycle to the first bus stopthe one furtherest away-because, based on experience, the bus's bicycle rack is likely to be full at the other stops.

Stepping back, in this example we also see a structural coupling, that reality is enacted through a moment-to-moment decision-making process, and that much practical knowledge is needed. One obvious, if relatively superficial, difference is that the action takes place in a world of mechanical and digital tools, with several thousand evening commuters all seeking bus transportation. For the designers of the app, a key consideration is the granularity of the representation of the bus and its movements. More contextual information about the bus (updated details about seating and bicycle rack availability) might simplify decision-making, improve accessibility, and increase the number of bus commuters (beneficial for the environment), but at the cost of more digital infrastructure (harmful). Responsible engineering will likely require ethical public participation among stakeholders, who might include commuters, technologists, university administration, state government, and engineering organizations.

Scenario 3: Migrating maples. Based on models of the Intergovernmental Panel on Climate Change [70], the regional distribution of trees in the central and eastern U.S. is expected to change (see Figure 3). Notice that the projected map shows the near disappearance of maple trees from the Northeastern states by 2070-2100. For many people, maple trees hold significance, not only for the commercial value and the pleasurable taste of maple syrup, but also for summer shade and fall beauty, for furniture-making and woodburning stoves, and for many other things [34, pp. 167-174].

Stepping back, this example reveals the expected impact of planetary forces on places, and it makes a prediction about the future. For people who depend upon or revere maples, or just enjoy their company, this map might be devastating because it represents the possibility of irretrievable loss. Today and into the future, people can seek relational experiences with maple trees. But, is caring for maples futile? In some ontological futures, yes; in others, perhaps

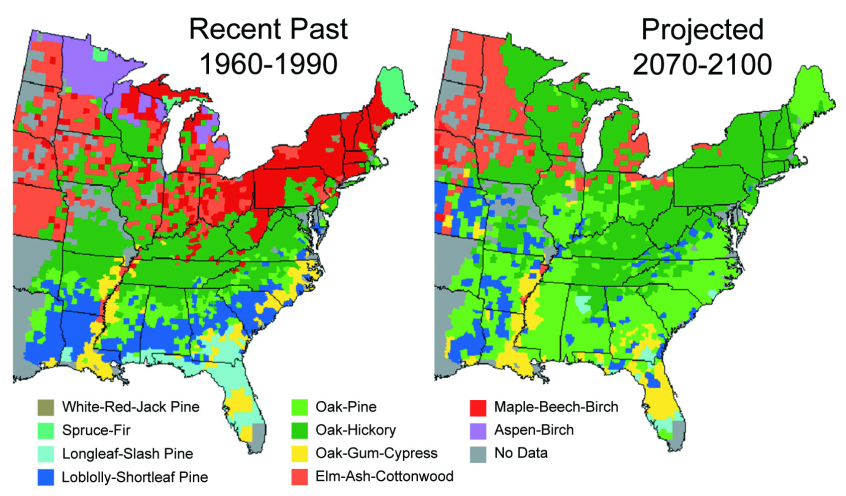

Figure 3: Predicted tree migration. Credit: U.S. Global Change Research Program [71]. Cropped and titles redrawn.

not. Accordingly, long-term cultural adaptation is a key consideration; for example, psycho-social interventions for managing grief; inventing rituals, for example, pilgrimages north across the border during sugaring season; genetically modifying maples; and so on ${ }^{3}$.

Brief summary. With ontological design, individuals and societies design themselves by the shaping influence and processional structure of language and tools. The examples show how reality emerges from design elements, unbounded in type and quality. Even with these straightforward accounts, we see profound considerations related to intervention, including precautionary and prudent responses, for example, leave well enough alone (Scenario 1); ethical participation and responsible engineering (Scenario 2); and long-term political preparation for cultural change (Scenario 3).

It is also noteworthy that all of these examples concern future generations, indicating the importance of long-term thinking and multi-lifespan design [17]. Indeed, with ontological-oriented inquiry, design is always concerned with future generations, since the work done now creates the conditions for those who follow. Finally, ontologically oriented commitments do not necessarily mean giving up on accepted methodologies. Rather, ontological analysis and design gives insight into the interactional stance [15], which underlies, either explicitly or implicitly, many approaches to sociotechnical analysis and design, as well as engineering.

\section{INTERLUDE AND METHOD}

Some of Escobar's theorizing [12, chaps. 4-5] has been introduced in sections 3-4, and the three working scenarios give simplified accounts of situations with which to think and imagine. For the remainder of the paper, I turn to LIMITs.

Recall the motivating proposition from the introduction: LIMITS is an information system of discourse about transitions. Building on this and the background, I came to a focusing question: How do language and tools in the LIMITS papers address transitions?

With this framing, I spent about 20 hours browsing the LIMITs papers from 2015-2020. I read most of the abstracts, taking notes

\footnotetext{
${ }^{3}$ I am aware that the impacts of expected sea-level rise, including the forced migration of hundreds of millions of households by the end of the century, will likely be far more serious in comparison to this example $[25,56]$. Also, although anticipatory and simulated, in essence this example is common: Indigenous Peoples have witnessed the destruction of countless ecosystems over more than two centuries.
} 
Table 1: Summary of Eight "Food” Papers from Limits.

Short Title and Brief Description (ordered by publication date)

(1) Permatopia [23]. Design of communication system for supporting a permaculture village (2020).

(2) Storytelling Chair [9]. An exploration of digital mediated storytelling in The Lions' Gate [10], a permaculture garden (2020).

(3) Lions' Gate [10]. Design of permaculture garden, with physical and virtual components, on a university campus (2019).

(4) $S A G E-C C$ [48]. Design of information system for coordinating sustainable polycultures among urban neighborhoods (2019).

(5) DIY Smart Garden Kit [53]. Pedagogically-oriented project on digitizing residential gardens for optimal use of water (2018).

(6) Food Tracking [42]. Analysis of analytic and narrative affordances of representing food supply chains (2018).

(7) Out of Control [36]. Ethnographic study of two Taiwanese farmers who follow permaculture principles (2018).

(8) Smallholder Farms [79]. Field work to develop technical requirements for data sensing and data networks on farms (2017).

and tallying 82 research articles. I read a selection of papers. I was drawn to the website's photographs and themes, and, as might be expected of a workshop series, I found it difficult to obtain a gestalt-I did not find a conceptual map of LIMITS.

Given practical constraints, namely I would be working alone and total time would be about 140 hours, my analysis would be exploratory, perhaps a first step in a deeper level of analysis. I also needed a bounding strategy: I noted that $8 / 82$ papers concerned food, with the papers covering the 2017-2020 meetings (see Table 1). These eight papers, in turn, cite three additional papers from LIMITS, all in 2015-16 [7, 22, 52].

In addition, I was working on a food resiliency project, and knew that food systems contribute about $25 \%$ of global anthropogenic greenhouse gas emissions and the impact of climate change on food systems is expected to be profound [72]. Furthermore, there is a presumed need for information systems that "enable us to renew and broaden our efforts to secure a more sustainable and healthy food system for our own and future generations" [2, p. 7]. Hence, "food" papers seemed to be a reasonable point of focus.

To direct my inquiry, I drew upon value sensitive design theory [15], especially the envisioning criteria [44] [15, pp. 162-164, authored by Lisa Nathan] and multi-lifespan design [17, 77]. These two frameworks offer a systemic view of socio-technical systems, existing or envisioned. The four criteria-stakeholders, values, time, and pervasiveness-underpin the Envisioning Cards toolkit [14, 16], and other methods in value sensitive design.

Then, I sketched a very simple, qualitative lens. First, to the four envisioning criteria, I added more specific topics from Escobar [12], as shown in parenthesis: (1) STAKEHOLDERs (Consider non-human beings, Consider how human beings are designed); (2) values (Consider relationality and attunement to Earth); (3) TIME (Consider time horizon); and (4) PERvASIVENESS (Consider the scale of worlds, Consider coordination among worlds). Next, I included a category on (5) INTERVENTIONS, to consider how the project was involved in the world and with stakeholders. Then, I included a category on (6) LIMITs, to consider dichotomies, dualisms, gradations, limits, spectra, thresholds, and tolerances. Finally, I included a category on (7) WORLDVIEws, to consider how the past, present, and future are integrated in narrative. With these seven categories, I read and considered the eight food papers, along with other LIMITs' papers.

Methodological note. These categories are not used in qualitative coding or the like; instead, they provide an orientation for selecting noteworthy features and for writing the project portraits, where like a traditional portrait of a person, I seek an accurate likeness of the project while also highlighting some features.

\section{PROJECT PORTRAITS}

Here, I summarize the eight papers (seven projects), ordered roughly by scale, from tiny places (an indoor planter) to the planet (representations of international food networks).

DIY Smart Garden Kit [53]. In this project, the authors envision a world where home horticulturists have fine-grained control over the growing conditions of vegetable gardens. In their technical investigation, the garden is modeled by an indoor planter box, instrumented with moisture sensors, and connected to an Arduino microcontroller, which responds to changes in moisture, and controls a pump, which waters the planter. Software was written for the home gardener to monitor the garden and operate the technology. Undergraduate students developed and studied the technology over four months, keeping a written project diary about the planter. The entries refer to plant growth, color, smell, and "critter status" (i.e., insects that damage plants), along with breakdowns of all kinds and workarounds ("soldering research," "Wifi problems," "flipped the polarity [of a temperature/humidity sensor] causing a short," using vinegar to "get the damn pests away," etc.). Simply put, the diary and planter box seem mutually constitutive. The diary reveals students' curiosity; concern for and care of living things, digital materials, and algorithms; and the expression and development of practical know-how. In this envisioned world, cybernetic control and feedback [75] if widely deployed in home gardens will lead to water savings that will accrue across society.

Out of Control [36]. In this ethnographic field study, permaculture values and practices are considered alongside the "control model." Like the hunter and moose (Scenario 1 above), a farmer is shown to be structurally coupled with tea plants, and brings much know-how for working with and caring for tea. The orientation is relational and biocentric, where humans are placed "into the ecology as actors not controllers" [p. 5]. Liu et al. describe in exquisite detail how small insects, called leaf hoppers, feed on tea leaves, which causes damage. As the plant repairs the damage, the tea leaves are changed to contain compounds that produce a "natural honey scent during tea brewing” [p. 3]. The damaged leaves also attract spiders, who eat the leaf hoppers. Thus, the pleasure of brewing and drinking this tea depends on a fine balance among the tea plants, the leaf hoppers, and grasshoppers, for if the leaves are not damaged the honey scent will not develop. However, if the leaves receive too much damage the tea will be bitter. While the farmers largely cede control to natural processes, that is, they observe the impact of leaf hoppers on the tea leaves, it is interesting to consider what kind of interventions would be consistent with 
the philosophy of permaculture (e.g., an infestation of leaf hoppers, the absence of leaf hoppers or spiders). The farmers demonstrate commitments to the values of "appreciation, affection, and responsibility" [p. 4], similar to the students who worked on the DIY Smart Garden Kit project.

Lions' Gate [10] and the Storytelling Chair [9]. An investigation of permaculture place-making, this project unfolds on the grounds of Edinburgh Napier University. The goal is "to embed permaculture as a research framework within the superstructure of the university... to make a fundamental shift in thinking toward addressing human and planetary wellbeing" [p. 1]. Lions' Gate is a multiuse setting, which blends permaculture, physical space, and virtual space. It comprises gardening infrastructure (soils, raised growing beds, water), furniture (benches, chairs, and tables), specialpurpose spaces (an outdoor classroom, an indoor studio-like space), digital infrastructure (microclimate sensors, data and power feeds), and a volunteer policy. In this "speculative context," human beings, plants, and non-living entities are in a shifting web of relationships. Within this web, a focal point is the storytelling chair, which invites people to discuss sustainability and living symbiotically with nature, for local and global listeners. Like the DIY Smart Garden $K i t$, this formative intervention seeks to create coherence from a mixture of the living and non-living.

Permatopia [23]. Using design research methods, this project is an investigation into how to support communication at Permatopia, Denmark, a permaculture community of 90 households, in which all community members over the age of 15 contribute 2 hours per week to growing food and community resilience. A shared diary is used by individuals to record observations about farm work, to ask questions, to give instructions, and so forth. Similar to the DIY Smart Garden Kit project diary, this diary and other written records reveal a relationality between land and farm workers, focused on conditions, farming tasks, and responses. A key design insight of the research was that "data follows action, not people" [p. 281], that is, completed work tasks are tallied, and then represented for the community at large, which, in turn, allows for collective action (shared goals and joint intentionality).

SAGE-CC: Software for Agriculture Ecosystems Community Coordinator [48]. Part of multi-year research on the design of sustainable polycultures [49], like Permatopia, this project is instrumental; specifically, it seeks to support the optimized selection of plantings. However, rather that seeking to support the values of an intentional community (a somewhat autonomous world), SAGECC operates at a regional level, across thousands of households, structured in urban neighborhoods. Accordingly, if each household is considered an autonomous world, this project confronts a major question (which is also confronted by the pluriverse): How do households communicate with each other? And relatedly, how, if at all, are hierarchical structures formed? Both of these questions are essential because sustainable polycultures are spatially large (regional-scale) and hierarchically structured [48]. The project builds, in part, on a earlier study [66], of the spatial distribution of urban agriculture sites in Chicago, Illinois, US, an area of more than 600 $\mathrm{km}^{2}$. By the analysis of satellite imagery over 4,500 food producing sites were identified, including 4,001 residential gardens (Figure 4). By modeling the ecological conditions of the region, the relationships among specific plants, the availability of pollinators,

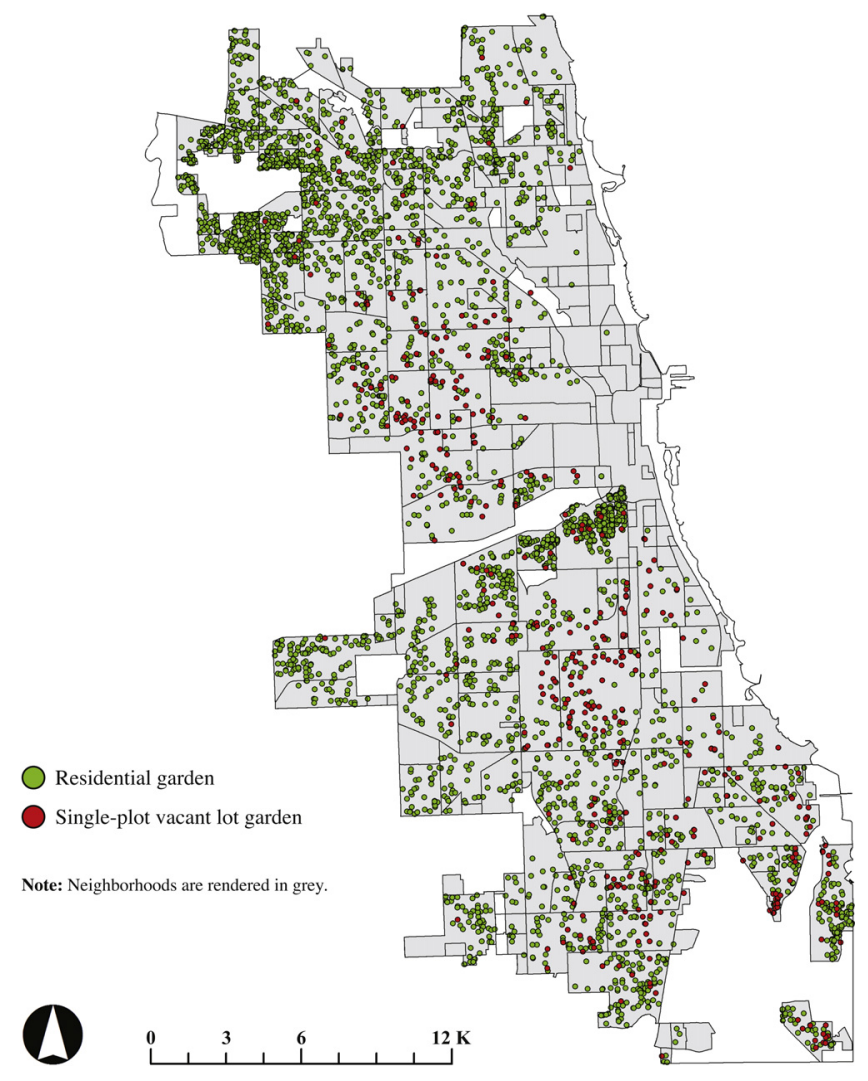

Figure 4: Residential gardens in Chicago, IL, by analysis of satellite imagery. Credit: Taylor and Lovell [66].

the spatial structures of residential gardens, and so on, Norton et al. design algorithms and a user-interface that recommends new plantings to owners of residential gardens. The objective of the modeling and design of individual gardens is to optimize the beneficial relationships among plants, hierarchically across the region, thereby promoting a sustainable polyculture. With this ecological services framing, residence-to-residence coordination is essential so that plants that are mutually beneficial are placed in optimal proximity. Beyond the opportunity for collective action for gardening and plant selection, Norton et al. note that the system might be designed to enable other aspects of food and gardening (e.g., sharing materials, labor, food knowledge, etc.)

Smallholder Farms [79]. To produce more food, more efficiently, and with less environmental impact requires that farming operations be modeled in realtime. Beginning with this thesis, a cybernetic vision is presented, where agricultural land is wired with sensors for dynamic monitoring and control. At the most granular, hypothetically, individual plants in a strawberry field might be ID'd, their productivity and conditions monitored and, when necessary, their growth boosted by the optimized application enough water, insecticides, and so forth. Or, on an organic farm, perhaps the anatomical movements of draft horses are sensed, to monitor their well-being and to adjust workloads accordingly. Zheleva et al. demonstrate that one key to precision agriculture is to uncover the specific requirements of the data networks, how data is produced 
by non-human animals, living things, (e.g., plants, soils, etc.), infrastructure (e.g., fences, gates, flowing water, etc.), and human labor. Digital technology, deployed and appropriately shaped, might serve the goals of permaculture, industrial agriculture, or other forms of farming.

Food Tracking [42]. This project turns to planetary scale, and considers the origins and movements of food through international supply chains. In this work, we see the separation of planetary and place-based representations but also the means for considering the interconnections between the two. Food tracking is shown to address the goals and values of diverse stakeholders, including government agencies concerned with food quality and safety, and consumers and retail shops who value trust and accountability and authenticity. Tracking systems hold the potential for analytic investigations (Life Cycle Assessment analysis, summarize of energy and greenhouse gas emissions), along with place-based accounts of food and farming (families from the Global South who supply ingredients for products made in the Global North). The technical and conceptual considerations are wide ranging, from the integrity of data from dynamically changing sources, to the validity of the models for estimating $\mathrm{CO}_{2}$ emissions, to how written and visual stories about food are represented

\section{DISCUSSION}

\subsection{Worldviews and Transition Discourses}

Presenting a historical account, Charles Mann [39] traces how two different worldviews for growing food have clashed scientifically, ideologically, and practically for decades. On the one side are the Wizards, personified by agricultural scientist and proponent of industrial agriculture, Norman Borlaug, the other are the Prophets, personified by the influential ecologist, William Vogt. The Wizards are the nature conquerers, who reduce land to a material stockpile and pursue scientific discovery and technological innovation to increase land productivity. In general, negative "side effects" are ignored or put to the future, and a fundamental contradiction is left unaddressed: "the techniques, innovations, practices, and policies that constitute industrial agriculture, and which have played the largest role in increasing agricultural productivity, have also undermined the basis for that productivity" [20, p. 3]. Their work led to the 1960s Green Revolution and the Nobel Peace Prize (Norman Borlaug, 1970); industrial and precision agriculture; the concentration of power and economic wealth in a few transnational Big-Ag companies. The Smallholder Farms project seems to generally fit here, framing agriculture as growth within limits.

The Prophets, on the other side, question the success and longterm viability of industrial agriculture, noting the very serious problems that loom today [54]. They see the planet as small and vulnerable; they decry technologies that separate people from Earth. Land carrying capacities, production yields, and other reductionistic measures are rejected in favor of wholistic understandings of ecologies and sensitive interventions that lead to long-term sustainability. Drawing on the science of agroecology [20], their work includes organic farming (beginning in the early 1940s), civic agriculture, permaculture, and local food movements [39]. Four of the projects, Out of Control, Lions' Gate, Permatopia, and SAGE-CC, build upon permaculture, and thus fit within this worldview.
The remaining two projects are less easily categorized. The $D I Y$ Smart Garden Kit seems to lie in the bewildering middle-ground between Wizards and Prophets, for this project employs digital technology narrowly, augmenting the human hand and senses, and helping gardeners to interact with and learn about soil. Thus, it might be considered a convivial tool [29]. The Food Tracking project, in contrast, bridges the worldviews, modeling the sustainability of foods, no matter their origins, in a unified representation.

I turn now to worldviews that make up transition discourses. The word transition means "a passing or passage from one condition, action, or (rarely) place to another," [67]. As a conceptual metaphor, it represents movement from a beginning steady-state through a liminal middle period to an ending steady-state. Like all metaphors, it raises questions. If, for example, "a transition" is a cord, where does it start and end, how many strands are woven together, and how long is it? As transitions unfold in parallel, how do they relate? And so on.

In any case, like the transition discourses reviewed by Escobar [12, chap. 5], Macy and Johnstone [38] fill in the transition metaphor with particular claims about the past, present, and future. They note that Business As Usual (market economic growth) and the Great Unraveling (economic decline, resource depletion, climate change, social division and war, mass extinction of species) are two accounts of reality that simultaneously exist. To these, they add the Great Turning, a program of practical action, structured around three dimensions: (1) Holding actions (e.g., "protect what is left of our natural life-support systems," "care for those who have been damaged," etc.); (2) Life-sustaining systems and practices (e.g., "triple return investments," "community supported agriculture," and other new tools and social structures); and (3) Shift of consciousness (e.g., developing a "wellspring of caring and compassion," change in perceptions and values, etc.).

Stepping back, what do we learn by setting the seven projects side-by-side these worldviews? First, with the possible exception of Smallholder Farms, all of the projects appeal to the Great Unraveling to motivate research. Second, all of the projects except Smallholder Farms seem largely consistent with the values and practical actions of the Great Turning. Third, confronting the Wizard worldview, as does transition discourse in general [12], all of the projects, except Smallholder Farms and Out of Control, use technology instrumentally and/or formatively for local practical action. This is noteworthy because Macy and Johnstone do not take up the role of technology in their conceptualization of transition; thus, here is a common area of complementary knowledge and practice. Forth, returning to the descriptive dimensions of ontological design (section 3), we can identify many elements in operation-designing designers at Lions' Gate; creating ontologies out of a mixture of elements with the DIY Smart Garden Kit; the shaping influence of the $S A G E-C C$ application; the processional structure of planning for and completing tasks with the diary at Permatopia; and so on.

\subsection{Transition Discourses and Time}

Transitions, as we have seen, set the conditions for systemic, manifold change. It takes time to set-up conditions, and it takes time for them to have an effect, although there are no guarantees, since alternative worldviews vie for influence, the impacts are emergent, 
and so on. Nevertheless, a central element of transitions is how time is conceptualized. Macy and Johnstone [38, chap. 8], for example, take a "larger view of time," noting that contemporary ways of being are in opposition to long-term thinking and action. They suggest a shift in consciousness, to think ahead seven human generations (about 140-200 years).

Working with time in design processes is a substantial area of inquiry [5, 17, 18, 31, 37, 74, 77]; its treatment here will be limited. That said, I briefly unpack three salient aspects of time.

Project intervention time horizons. In general, the project durations are short. The $S A G E-C C$ project reports on a 3-day workshop, which of course, fits within a broader, multi-year research project. The DIY Smart Garden Kit took place over a single summer. The Smallhorlder Farms project collected data for about one year. The Lions' Gate project has been developing for several years.

In addition to project duration, we can also consider the expected evolution of projects. On this, the papers generally contain few details. That said, for Lions' Gate it is a concern: "Persuading the university to take a long-term view of The Lions' Gate is a constant battle" [10, p. 7]. The Smallholder Farms project is shaped by the technological innovation cycle and market opportunities; thus, its time horizon seems to be both short and long. That is, the specific technical requirements and working solutions, once identified, can be put to immediate use or shelved for the future, when conditions allow for or necessitate their use.

Stakeholder time flows. The Permatopia project engages with an intentional community that is just getting started. While future plans were not reported, a long time horizon is embedded in the philosophy of permaculture ("each member of a permaculture community is on a continuous journey of learning" [23, p. 276]) and the effects of seasonality, reflected in yearly rhythms of work, are a hallmark of agriculture. In this regard, diary entries become more valuable the longer they exist. In ten, fifty, or two-hundred years the diaries of farm work, if accessible, will reveal much of the existence and future of Permatopia. The SAGE-CC project notes that sustainable agriculture has been a decades-long effort; accordingly, the same likely holds for the design of regional agroecosystems.

Transition time horizons. The "transition" metaphor, as movement from beginning to end, raises a troublesome question: When will we be done? The "turning" metaphor offers an elegant response, since we can move around an axis indefinitely, like Pluto rotating around the sun or the Seattle Ferris Wheel. Indeed, the dimensions of the Great Turning focus on immediate personal and community work, pursued in an actively hopeful manner, similar to M. Six Silberman's six extremely insightful heuristics for information system design for the moment [62]. (See also Jay Chen, who discusses urgent tangible problems [7].)

Stepping back, the seven LIMITs projects by and large do not make explicit commitments to time, either in design processes or in transition discourses. Setting design work within two, three, or more human generations opens new opportunities [17, 77]. More broadly, with respect to climate and food, a paradox is apparent: The time for dilly dallying is over; nevertheless, the things we set into motion now will unfold over future human generations. Hence, Macy and Johnstone's dimension, "Shift of Consciousness" is notable. Finally, placing technical work-demonstrations, design insights, design methods, etc.-within transition discourse might help better situate computing research and design, a challenge to LIMITS scholarship noted by Kaczmarek et al. [33].

\subsection{Interventions: Instrumental and Formative}

As introduced in sections 4-5, "interventions," that is, how a designer configures an engagement with a place or system, is a central consideration. Six of the projects (not Out of Control) either intervene instrumentally, formatively, or both.

The design researcher in the Permatopia project served the community, seeking communication systems that are sensitive to the community's values. Thus, the design insight that "data follows action, not people," is an indication that the community comes first, which also led to distinctive requirements. A communal worldview [1] such as this, where family is secondary and the individual is tertiary, opens opportunities to reconsider data, technology, and social action. In some ways, the Smallholder Farms project is similar in that researchers worked within a bounded site, Essex Farm, a privately owned 1,100 acre farm [13, 30]. Unlike the Permatopia project, however, the project focused on identifying general infrastructure requirements, not on the specific values and activities of Essex Farm. Both projects are instrumental and bounded, but differ in an important way: The Permatopia project is embedded and value sensitive, whereas the Smallholder Farms project largely takes Essex Farm as a system for technical investigation.

Lions' Gate, on the other hand, is formative. While it seeks a "fundamental shift in thinking" within an institution, it is not clear how the space occupied by the Lions' Gate garden and its programming will lead to institutional change. While it might do so, the intervention seems precarious, in part, because the stakeholdersinstitutional and grassroots-and their power relations are not represented and shown to be part of the design process.

With the SAGE-CC project, the stakeholders and the configuration of possible interventions are still murkier. Figure 4 constructs circumstances and opportunities, where each dot represents a home and family, along with an address, a property value, and other objectifying variables. Further, with additional technical work, perhaps details about the gardens can be extracted from the aerial imagery (e.g., the number and type of plants, watering schedules, use of fertilizers and insecticides, height of fences, etc.). Cleaned and integrated, this data might be very helpful for designing regional polycultures. But a more fundamental question might be: What do families think about their gardens being mapped? In sum, the $S A G E-C C$ project is instrumental and formative.

A final illustrative example is the work on $\mathrm{CO}_{2}$ emissions and academic flying [51], a demonstration of the viability of immediate practical work for institutional adaptation. The essential idea is to model an institution's $\mathrm{CO}_{2}$ expenditures, for prioritizing options for institutional adaptation. As units within an institution reduce emissions, for example, by flying less, the savings fold up to the institution, to the nation state, and to the Paris Agreement, an instrument that represents planetary limits. In thoughtful research and practice, Pargman et al. conclude: "The Carbon Law implies fundamental, tough and probably also potentially painful changes to academic (travel, career) practices also on a time scale of only 5 or 10 years" [51, p. 289]. By means of this transition system, it was found that a good deal of $\mathrm{CO}_{2}$ expenditure comes from visitors 
who fly to the university; for example, the members of the $\mathrm{PhD}$ grading committees. Thus, the procedures of Swedish doctoral education and the "opponent system" will need to change. Will it be painful? Perhaps, yes. But, if the situation is framed as an ontological transition-where the traditions of the Swedish doctoral education are to be honored, where $\mathrm{CO}_{2}$ emissions are to be severely limited, where the changes are to be planned for the next 10-20 years, where pain, grief, and other emotions are taken as elements of the design situation, and where the process of change is to be joyful and convivial-perhaps not.

Stepping back, in many instances computing research seems to produce results, which open new design situations, which require different disciplinary expertises and skills. The migrating maple trees, the design of a regional agroecosystem across urban neighborhoods, and the remaking of the Swedish "opponent system" are all examples of long-term cultural adaption. While each is caused by climate change, the proximate catalyst for change comes from computing research and design. In the coming decades it seems likely that there will be an untold number of projects like these, in institutions and the built environment, where computing research and other disciplines will collaborate.

\subsection{Limits: Planet to Place, and Back Again}

LIMITs has been concerned with planetary limits [7, 43], especially those rooted in geophysical processes [57]. Within agriculture, such limits can be expressed with the variables supply and demand for food calories, under given climatic conditions [2, p. 7]:

Planetary limits: The global community must operate within three limits: the quantity of food that can be produced under a given climate; the quantity needed by a growing and changing population; and the effect of food production on the climate.

One of the seven projects, Smallholder Farms, firmly appeals to this planetary view, beginning: "with the world's booming population, the United Nations foundation estimates that the farm production needs to double by the year 2050 for society to be able to eradicate hunger" [79, p. 59]; and, concluding: "to tackle this problem, we need to increase agricultural production, while dramatically reducing its environmental footprint" [p. 67]. The proposed solution is granular sensing, modeling farm operations, and control. Despite material and energy costs, precision agriculture might, in other words, "fix" industrial agriculture and advance it.

However, this approach, like the DIY Smart Garden Kit project, might also be instrumental to the goals of other forms of agriculture. Notably, Essex Farm [13, 30], the research site for the Smallholder Farm project, is not a site of industrial agriculture. Rather, its owners make commitments to long-term sustainability, organic farming, ethical treatment of animals, healthy eating, and yearround community-supported agriculture, but the values underlying these commitments are not found in the research reporting, unlike, for example, the work a Permatopia.

The Limits workshop series has also worked with other kinds of limits. For example, in a study of transitions, Xinning Gui and
Bonnie Nardi [22] identified three categories: psychological limits, knowledge and skill limits, and social limits ${ }^{4}$. The third category, social limits, refers to those imposed by institutions, political systems, and culture. These are not planetary limits; instead, they are local, place-based limits, and to counter them the authors recommend: "more community, more shared activity, more collaborations, more shared moral sense of sustainability, more neighborliness, more empowerment" [22, p. 4]. Similarly, Doug Schuler [60] develops several categories of social limits, related to the structure of institutions, myths, disempowerment (and lack of imagination), and inequality. To counter these, according to Schuler et al., is a matter of civic intelligence, that is, collective knowledge and action directed at local problems, skills that can be developed through community-focused pattern languages [61].

All seven of the food projects substantially engaged social systems that emerge from a place. In this vein, consider these three questions, asked by Wendell Berry, the American farmer, conversationalist, and celebrated writer [3, p. 142]:

Place-based limits: There are, I think, three questions that must be asked with respect to a human economy... 1. What is here? 2. What will nature permit us to do here? 3. What will nature help us do here?... if we do not work with and within natural tolerances, then we will not be permitted to work for long.

The second and third questions are tied to taking local action and working within "tolerances," not a floor or ceiling as a "limit" might be but an acceptable range. But, these two questions depend on an answer to the first question, "what is here?" This question might be addressed by a land ethics, a conjunction of the natural and the human, or in other ways. In whatever manner the question is answered, it brings forth a reality, which conditions local actions. If, for example, soil is largely considered to comprise levels of nitrogen, potassium, and phosphorus we move in one way. If, however, soil is seen as a teaming web of life, which currently defies full scientific understanding, we move differently.

In short, both the planetary and place-based views are openings for ontological analysis and design. The planetary view leads to a program of technical rationality, the hierarchical decomposition of limits, optimization of objective functions, and so on. In so doing, a profound question is answered, namely "what is the planet?" Berry's (ontological) questions might lead differently.

Stepping back, I would like to make three general points. First, tensions between place-based and planetary views dominate the seven projects. For example, on the one hand, the careful ethnographic work of tea cultivation and permaculture practices ("Out of Control") clarifies working with and caring for relationships; on the other, is the question: Can permaculture produce sufficient food for large numbers of people, many who live in urban communities, while not unduly increasing the land area devoted to agriculture? On the one hand, the DIY Smart Garden reveals a caring approach to understanding soil and water with digital instruments; on the other, is the question: What material impacts would arise if tens of

\footnotetext{
${ }^{4}$ To motivate multi-lifespan design [17], Friedman and Nathan proposed similar limits: (1) limitations to human psyche, (2) limitations of the structure of society, and (3) natural time-scales that move more slowly that a single human lifespan.
} 
millions of people used such instruments to save water in the backyard gardens? By and large, transition discourses seem to resolve planet-place tensions by emphasizing practical actions in places, while largely ignoring technology and its material impacts [see 4].

Second, the answer to "what is here" is crucial. Like Churchill's argument for rebuilding the House of Commons, it shapes the future because it shapes what ought be done in the present moment (section 3). The importance of considering interventions ontologically becomes even clearer when they are framed by multiple human generations and learning within and across generations.

Third, the two views shape reality. Note that the planetary view refers to the "global community," to which I think Escobar would object, since hegemonic structures destroy places, which is inconsistent with a pluriverse. On the other hand, the place-based view refers to a "human economy." Here, Berry is asking for a reformed economics, which accounts for values related to sustainability, human well-being, and dignity. This clash of views raises the question: How, if at all, might place-based and planetary views be integrated? The Food Tracking [42] project answers this question, by showing a way to flexibly represent shifts in perspective, from farms and farmers to global supply chains, to planetary $\mathrm{CO}_{2}$ emissions. Similarly, the Academic Flying project represents the planet, by the Paris Agreement, and moves down through nation states to institutions to particular practices that produce $\mathrm{CO}_{2}$, illustrating a representational approach that seems widely applicable [51].

\section{CONCLUSION}

To briefly recap, first, ontological design creates worlds, which condition reality. Second, many worlds coexist in the pluriverse, where worlds are autonomous and where differences between worlds are respected and nourished [12]. Third, adding depth to the interactional stance [15], ontological design and analysis can be used descriptively to investigate processes or it can be used formatively to structure design activities $[12,76]$. Fourth, transition metaphors and narratives are filled in with particular worldviews and normative claims for the past, present, and future. Fifth, transition discourse includes tools and conversations, stakeholders and values, conceptions of time and materials, and design elements of all kinds. Finally, six, the envisioning criteria $[15,44]$ can be used to give perspective for investigating systems ontologically, in a generative and constructive manner.

How do language and tools in the LIMITS papers address transitions? Returning to the question, with the possible exception of Smallholder Farms, the LIMITs projects on food are generally consistent with the Great Turning worldview and with Escobar's fivepart normative position on transitions (section 4), albeit some projects more so that an others. The projects, however, do not explicitly engage with multi-lifespan horizons nor with the material impacts of scale. Further, putting aside Smallholder Farms, the projects do not explicate how socio-technical interventions or possible solutions contribute broadly to transitioning to a sustainable future. In contrast, by building from the Paris Agreement, the academic flying project [51] does explicate a targeted framing for making broad change. These three openings for project framing-time, scale, and transition discourse-would seem to merit inquiry and discussion within the LIMITS community.
While the pluriverse offers direction for conceptualizing transitions, the LIMITs papers reviewed also suggest very difficult questions about the pluriverse. For one, how might nascent or fragile worlds be given freedom to develop? Securing a degree of autonomy, for example, at Lions' Gate or Permatopia, seems to require long-term political structures that lie outside the boundaries of these places. For another, how might regional or planetary-scale efforts be coordinated in the pluriverse? Such efforts would seem to require hierarchical structures to manage complexity and communication. The SAGE-CC project, where regional agroecosystems are to be designed, is illustrative of this difficulty. Finally, perhaps most importantly, what might to be done when one dominate world blocks, takes over, defutures, or destroys other worlds? Industrial agriculture appears to be such a case. These kinds of questions ask for new research and the development of practical approaches.

Relatedly, interventions within transition design present ethical and moral questions of perplexing difficulty, not least because the purpose of transition design is to catalyze systemic change, to change culture and traditions. Being embedded and engaged within an organization and using technology to further social action provides a socio-political position for making principled decisions $[8,62]$. A place-based community such as Permatopia is a prototypical example, a somewhat autonomous world within a world [12]. However, ecological and food systems cross political boundaries and activist groups can express solidarity for different goals. Thus, theory and methods for engaging in ethical public participation and social coordination across groups and communities are of urgent importance. Developing such methods and creating the democratic and social conditions for their acceptance is a longterm project [e.g., 60, 61, 78].

Winograd and Flores [76] emphasize the representational capacity of computers to transform traditions through the creation of new language and new spaces for interaction and conversation. With millions of organizations seeking more sustainable ways of being and acting [26], with complex relational linkages between planetary and place-based views, and with the heightened need for collective rationality, imagination, and will perhaps a central challenge for computing is to represent what we have, that is, to develop prudent answers to the question "what is here?" This is an ontological design situation; that is, "the world determines what we can do and what we do determines our world" [76, p. 177].

\section{ACKNOWLEDGMENTS}

I thank members of the value sensitive design reading seminar at the University of Washington, particularly Alan Borning, Stephanie Ballard, Ishita Chordia, Nathan Dors, Batya Friedman, Elias Greendorfer, Isaac Holeman, Rose Paquet, Nick Logler, Lassana Magassa, Lily Rajan, and Beck Tench for ongoing and multi-year conversations. I would also like to thank Lisa Nathan for recent thoughtprovoking presentations and for her doctoral dissertation which, after many years, has stayed with me. Finally, sincere thanks to my reviewers, and other colleagues, for very stimulating comments.

\section{REFERENCES}

[1] Jeannette Armstrong. 2012. Sharing one skin. In Asserting Native Resilience: Pacific Rim Indigenous Nations Face the Climate Crisis, Zoltán Grossman and Alan Parker (Eds.). Oregon State University Press, Corvalis, OR, 37-40. 
[2] J Beddington, M Asaduzzaman, A Fernandez, M Clark, M Guillou, M Jahn, L Erda, T Mamo, NV Bo, CA Nobre, R Scholes, R Sharma, and J Wakhungu. 2012. Achieving Food Security in the Face of Climate Change: Final Report from the Commis sion on Sustainable Agriculture and Climate Change. Technical Report. CGIAR Research Program on Climate Change, Agriculture and Food Security (CCAFS), Copenhagen, Denmark.

[3] Wendell Berry. 1987. Preserving wildness. In Home Economics: Fourteen Essays. North Point Press, San Francisco, 138-151.

[4] Alan Borning, Batya Friedman, and Nick Logler. 2020. The 'invisible' Materiality of Information Technology. Commun. ACM 63, 6 (May 2020), 57?64. https: //doi.org/10.1145/3360647

[5] Stewart Brand. 2008. Clock of the Long Now: Time and Responsibility. Basic Books, New York, NY.

[6] Rachel Carson. 1962. Silent Spring. Mariner Books, New York, NY.

[7] Jay Chen. 2016. A strategy for limits-aware computing. In Proceedings of the Second Workshop on Computing within Limits. ACM, Irvine California, 1-6. https: //doi.org/10.1145/2926676.2926692

[8] Sasha Costanza-Chock. 2020. Design justice: community-led practices to build the worlds we need. The MIT Press, Cambridge, MA.

[9] Callum Egan, Andrew O'Dowd, and Neil Fyffe. 2020. Hasten slowly: Developing an interactive sustainability storytelling chair. In Proceedings of the 7th In ternational Conference on ICT for Sustainability. ACM, Bristol United Kingdom, 321-329. https://doi.org/10.1145/3401335.3401817

[10] Callum Egan, Richard Thompson, and Andrew O’Dowd. 2019. The Lions' Gate: Towards a permaculture-inspired blended space. In Proceedings of the Fifth Workshop on Computing within Limits. ACM, Lappeenranta Finland, 1-8. https: //doi.org/10.1145/3338103.3338110

[11] Elina Eriksson and Daniel Pargman. 2018. Meeting the future in the past - using counterfactual history to imagine computing futures. In Proceedings of the 2018 Workshop on Computing within Limits. ACM, Toronto Ontario Canada, 1-8. https://doi.org/10.1145/3232617.3232621

[12] Arturo Escobar. 2018. Designs for the Pluriverse: Radical Interdependence, Autonomy, and the Making of Worlds. Duke University Press, Durham, NC.

[13] Essex Farm. [n.d.]. Retrieved March 20, 2021 from https://essexfarmcsa.com/

[14] Batya Friedman and David Hendry. 2012. The envisioning cards: a toolkit for cat alyzing humanistic and technical imaginations. In Proceedings of the 2012 ACM Annual Conference on Human Factors in Computing Systems - CHI '12. ACM Press, Austin, Texas, USA, 1145-1148. https://doi.org/10.1145/2207676.2208562

[15] Batya Friedman and David G. Hendry. 2019. Value Sensitive Design: Shaping Technology with Moral Imagination. MIT Press, Cambridge, MA

[16] Batya Friedman, Lisa Nathan, Shaun Kane, and Jon Lin. 2011. Envisioning Cards Value Sensitive Design Lab, University of Washington, Seattle, WA. http://www envisioningcards.com/

[17] Batya Friedman and L. P. Nathan. 2010. Multi-lifespan Information System Design: A Research Initiative for the HCI Community. ACM Press, 2243-2246. https://doi.org/10.1145/1753326.1753665 00041.

[18] Batya Friedman and Daisy Yoo. 2017. Pause: A Multi-lifespan Design Mechanism. In Proceedings of the 2017 CHI Conference on Human Factors in Computing Systems. ACM, Denver Colorado USA, 460-464. https://doi.org/10.1145/ 3025453.3026031

[19] Tony Fry. 1999. A New Design Philosophy: An Introduction to Defuturing. University of New South Wales Press, Sydney, Australia.

[20] Stephen R. Gliessman. 2014. Agroecology: The Ecology of Sustainable Food Systems (third ed.). CRC Press, Boca Raton.

[21] Greta Thunberg. [n.d.]. Wikipedia. Retrieved March 10, 2021 from https://en. wikipedia.org/wiki/Greta_Thunberg

[22] Xinning Gui and Bonnie Nardi. 2015. Foster the "mores", counter the "limits". In Proceedings of the 2015 Workshop on Computing within Limits. Irvine, CA, USA, 5 Pages.

[23] Anne-Marie S. Hansen. 2020. The App Is Not Where the Action Is: Discussing Features of an Internal Communication System for a Permaculture Village. In Proceedings of the 7th International Conference on ICT for Sustainability. ACM, Bristol United Kingdom, 275-284. https://doi.org/10.1145/3401335.3401824

[24] Terry Hartig and Henk Staats. 2003. Guest Editors' introduction: Restorative environments. Fournal of Environmental Psychology 23, 2 (June 2003), 103-107. https://doi.org/10.1016/S0272-4944(02)00108-1

[25] Mathew E. Hauer, Elizabeth Fussell, Valerie Mueller, Maxine Burkett, Maia Call, Kali Abel, Robert McLeman, and David Wrathall. 2020. Sea-level rise and human migration. Nature Reviews Earth \& Environment 1, 1 (Jan. 2020), 28-39. https: //doi.org/10.1038/s43017-019-0002-9

[26] Paul Hawken. 2008. Blessed Unrest: How the Largest Movement in the World Came into Being and No One Saw It Coming. Penguin, New York, NY.

[27] HC Deb 28 October 1943 vol. 393 cc403-73. [n.d.]. House of Commons Rebuilding. Retrieved March 10, 2021 from http://hansard.millbanksystems.com/commons/ 1943/oct/28/house-of-commons-rebuilding

[28] Marcella Horrigan-Kelly, Michelle Millar, and Maura Dowling. 2016. Understanding the key tenets of Heidegger's philosophy for interpretive phenomenological research. International fournal of Qualitative Methods 15, 1
(2016), 1609406916680634. https://doi.org/10.1177/1609406916680634 eprint: https://doi.org/10.1177/1609406916680634.

[29] Ivan Illich. 1973. Tools for Conviviality. Calder and Boyars, London.

[30] Rowan Jacobsen. 2015. How one farm saved Essex, New York. Eating Well (Aug. 2015). https://www.eatingwell.com/article/286374/how-one-farm-savedessex-new-york/

[31] Erich Jantsch. 1975. Design for Evolution: Self-Organization and Planning in the Life of Human Systems. G. Braziller, New York, NY.

[32] Daivd Johns. 2014. With friends like these, wilderness and biodiversity do not need enemies. In Keeping the Wild: Against the Domestication of Earth, George Wuerthner, Eileen Crist, and Tom Butler (Eds.). Island Press, Washington, D.C., 31-54

[33] Michelle Kaczmarek, Saguna Shankar, Rodrigo dos Santos, Eric M. Meyers, and Lisa P. Nathan. 2020. Pushing LIMITS: Envisioning beyond the artifact. In Proceedings of the 7th International Conference on ICT for Sustainability. ACM, Bristol United Kingdom, 255-266. https://doi.org/10.1145/3401335.3401367

[34] Robin Wall Kimmerer. 2013. Braiding Sweetgrass: Indigenous Wisdom, Scientific Knowledge, and the Teachings of Plants. Milkweed Press, Minneapolist, MN.

[35] Aldo Leopold. 1966. A Sand Country Almanac with Essays on Conservation from Round River. Ballantine Books, New York, NY.

[36] Szu-Yu (Cyn) Liu, Shaowen Bardzell, and Jeffrey Bardzell. 2018. Out of control: reframing sustainable HCI using permaculture. In Proceedings of the 2018 Workshop on Computing within Limits. ACM, Toronto Ontario Canada, 1-8. https://doi.org/10.1145/3232617.3232625

[37] Kevin Lynch. 1972. What Time Is This Place? MIT Press, Cambridge, MA.

[38] Joanna Macy and Chris Johnstone. 2012. Active Hope: How to Face the Mess We're in without Going Crazy. New World Library, Novato, CA.

[39] Charles C. Mann. 2018. The Wizard and the Prophet: Two Remarkable Scientists and their Dueling Visions to Shape Tomorrow's World. Alfred A. Knopf, New York

[40] Will Matsuda. 2021. Housing Projects And Empty Lots. How Chanell Stone Is Reframing Nature Photography. NPR: The Picture Show (Feb. 2021). https://www.npr.org/sections/pictureshow/2021/02/27/970992758/housingprojects-and-empty-lots-how-chanell-stone-is-reframing-nature-photograph

[41] Humberto R. Maturana and Fransisco J. Varela. 1998. The Tree of Knowledge: The Biological Roots of Human Understanding. Shambhala, Boston, MA.

[42] Meena Devii Muralikumar and Bonnie Nardi. 2018. Addressing limits through tracking food. In Proceedings of the 2018 Workshop on Computing within Limits. ACM, Toronto Ontario Canada, 1-9. https://doi.org/10.1145/3232617.3232620

[43] Bonnie Nardi, Bill Tomlinson, Donald J. Patterson, Jay Chen, Daniel Pargman, Barath Raghavan, and Birgit Penzenstadler. 2018. Computing within limits. Commun. ACM 61, 10 (Sept. 2018), 86-93. https://doi.org/10.1145/3183582

[44] Lisa P. Nathan, Batya Friedman, Predrag Klasnja, Shaun K. Kane, and Jessica K. Miller. 2008. Envisioning systemic effects on persons and society throughout interactive system design. In Proceedings of the 7th ACM conference on Designing interactive systems - DIS '08. ACM Press, Cape Town, South Africa, 1-10. https: //doi.org/10.1145/1394445.1394446

[45] National Oceanic \& Atmospheric Administration. [n.d.]. Trends in Atmospheric Carbon Dioxide: Mauna Loa, Howaii Readings. Retrieved March 10, 2021 from https://www.esrl.noaa.gov/gmd/ccgg/trends/mlo.html

[46] Richard Nelson, K. 1983. The Athabaskans: People of the Boreal Forest. University of Alaska Museum, Fairbanks, AK.

[47] Kari Marie Norgaard. 2011. Living in Denial: Climate Change, Emotions, and Everyday Life. MIT Press, Cambridge, MA.

[48] Juliet Norton, Birgit Penzenstadler, Samantha McDonald, Emily Kang, Nora Koirala, Rieko Konishi, Gabriela Pena Carmona, Jainee Shah, Sebastian Troncoso, and Bill Tomlinson. 2019. The SAGE Community Coordinator: A Demonstration. In Proceedings of the Fifth Workshop on Computing within Limits. ACM, Lappeenranta Finland, 1-10. https://doi.org/10.1145/3338103.3338108

[49] Juliet Norton, Birgit Penzenstadler, and Bill Tomlinson. 2019. Implications of Grassroots Sustainable Agriculture Community Values on the Design of Information Systems. Proc. ACM Hum.-Comput. Interact. 3, CSCW, Article 34 (Nov. 2019), 22 pages. https://doi.org/10.1145/3359136

[50] Martha Nussbaum, C. 2006. Frontiers of Justice: Disability, Nationality, Species Membership. Belknap Press, Cambridge, MA.

[51] Daniel Pargman, Aksel Biørn-Hansen, Elina Eriksson, Jarmo Laaksolahti, and Markus Robèrt. 2020. From Moore's Law to the Carbon Law. In Proceedings of the 7th International Conference on ICT for Sustainability. ACM, Bristol United Kingdom, 285-293. https://doi.org/10.1145/3401335.3401825

[52] Daniel Pargman, Elina Eriksson, and Adrian Friday. 2016. Limits to the sharing economy. In Proceedings of the Second Workshop on Computing within Limits. ACM, Irvine California, 1-7. https://doi.org/10.1145/2926676.2926683

[53] Birgit Penzenstadler, Jason Plojo, Marinela Sanchez, Ruben Marin, Lam Tran, and Jayden Khakurel. 2018. The affordable DIY resilient smart garden kit. In Proceedings of the 2018 Workshop on Computing within Limits. ACM, Toronto Ontario Canada, 1-10. https://doi.org/10.1145/3232617.3232619

[54] Tom Philpott. 2020. Perilous Bounty: The Looming Collapse of American Farming and How We Can Prevent It. Bloomsbury Publishing, New York, NY. 
[55] Steven Pinker. 2018. Enlightment Now: The Case for Reason, Science, Humanism, and Progress. Penguin Books, New York, NY.

[56] C. E. Richards, R. C. Lupton, and J. M. Allwood. 2021. Re-framing the threat of global warming: an empirical causal loop diagram of climate change, food insecurity and societal collapse. Climatic Change 164, 3 (Feb. 2021), 49. https: //doi.org/10.1007/s10584-021-02957-w

[57] Johan Rockström, Will Steffen, Kevin Noone, Åsa Persson, F. Stuart Chapin, Eric F. Lambin, Timothy M. Lenton, Marten Scheffer, Carl Folke, Hans Joachim Schellnhuber, Björn Nykvist, Cynthia A. de Wit, Terry Hughes, Sander van der Leeuw, Henning Rodhe, Sverker Sörlin, Peter K. Snyder, Robert Costanza, Uno Svedin, Malin Falkenmark, Louise Karlberg, Robert W. Corell, Victoria J. Fabry, James Hansen, Brian Walker, Diana Liverman, Katherine Richardson, Paul Crutzen, and Jonathan A. Foley. 2009. A safe operating space for humanity. Nature 461, 7263 (Sept. 2009), 472-475. https://doi.org/10.1038/461472a

[58] Joshua Rottman. 2014. Breaking down biocentrism: two distinct forms of moral concern for nature. Frontiers in Psychology 5 (Aug. 2014). https://doi.org/10. 3389/fpsyg.2014.00905

[59] Simon Schama. 1995. Landscape and Memory. Alfred A. Knopf, New York, NY.

[60] Douglas Schuler. 2016. Empowering limitations. In Proceedings of the Second Workshop on Computing within Limits. ACM, Irvine California, 1-6. https://doi. org $/ 10.1145 / 2926676.2926688$

[61] Douglas Schuler, Aldo de Moor, and Greg Bryant. 2020. New Community Research and Action Networks Addressing Wicked Problems Using Patterns and Pattern Languages. In Proceedings of the 7th International Conference on ICT for Sustainability. ACM, Bristol United Kingdom, 330-337. https://doi.org/10.1145/ 3401335.3401818

[62] M. Six Silberman. 2015. Information systems for the age of consequences. In Proceedings of the 2015 Workshop on Computing within Limits. Irvine CA USA, 6 Pages. https://computingwithinlimits.org/2015/papers/limits2015-silberman. pdf

[63] Chanell Stone. [n.d.]. Natura Negra. Retrieved March 10, 2021 from https: //www.chanellstone.com/natura-negra

[64] David Suzuki and Peter Knudtson. 1992. Wisdom of the Elders: Sacred Native Stores of Nature. Bantam Books, New York.

[65] Theresa Jean Tanenbaum, Marcel Pufal, and Karen Tanenbaum. 2016. The limits of our imagination: design fiction as a strategy for engaging with dystopian futures. In Proceedings of the Second Workshop on Computing within Limits. ACM Irvine California, 1-9. https://doi.org/10.1145/2926676.2926687

[66] John R. Taylor and Sarah Taylor Lovell. 2012. Mapping public and private spaces of urban agriculture in Chicago through the analysis of high-resolution aerial images in Google Earth. Landscape and Urban Planning 108, 1 (Oct. 2012), 57-70. https://doi.org/10.1016/j.landurbplan.2012.08.001

[67] transition, n. OED Online. [n.d.]. Oxford University Press. Retrieved March 10, 2021 from https://www-oed-com.offcampus.lib.washington. edu/view/Entry/204815?isAdvanced=false \&result=1\&rskey=AyHs6K\&

[68] Martina Tyrrell. 2010. Biodiversity and cultural diversity: The interdependent and indistinguishable. In Nature and Culture: Rebuilding Lost Connections, S. Pilgrim and J. N. Pretty (Eds.). Routledge, 123-144.

[69] University of Washington. [n.d.]. Campus Maps. Retrieved March 10, 2021 from https://www.washington.edu/maps/

[70] U.S. Global Change Research Program. [n.d.]. Global Climate Change Impacts in the United States 2009 Report. Retrieved March 10, 2021 from https://nca2009. globalchange.gov/index.html

[71] U.S. Global Change Research Program. [n.d.]. Global Climate Change Impacts in the United States 2009 Report: Projected Shifts in Forest Types. Retrieved March 10, 2021 from https://nca2009.globalchange.gov/projected-shifts-foresttypes/index.html

[72] Sonja J. Vermeulen, Bruce M. Campbell, and John S.I. Ingram. 2012. Climate change and food systems. Annual Review of Environment and Resources 37, 1 (Nov. 2012), 195-222. https://doi.org/10.1146/annurev-environ-020411-130608

[73] William Vogt. 1948. Road to Survival. William Sloane, New York, NY.

[74] Julia Watson and Wade Davis. 2020. Lo-TEK: Design by Radical Indigenism. TASCHEN GmbH, Cologne.

[75] Norbert Wiener. 1950. The Human Use of Human Beings: Cybernetics and Society A Da Capo Paperback, New York, NY.

[76] Terry Winograd and Fernando Flores. 1986. Understanding Computers and Cognition: A New Foundation for Design. Addison-Wesley, Boston, MA.

[77] Daisy Yoo, Nicholas Logler, Stephanie Ballard, and Batya Friedman. 2018. Multilifespan Envisioning Cards - Supplementary Set. Seattle, WA. http://www. envisioningcards.com/

[78] Meg Young, Lassana Magassa, and Batya Friedman. 2019. Toward inclusive tech policy design: a method for underrepresented voices to strengthen tech policy documents. Ethics and Information Technology 21, 2 (June 2019), 89-103. https: //doi.org/10.1007/s10676-019-09497-z

[79] Mariya Zheleva, Petko Bogdanov, Daphney-Stravoula Zois, Wei Xiong, Ranveer Chandra, and Mark Kimball. 2017. Smallholder Agriculture in the Information Age: Limits and Opportunities. In Proceedings of the 2017 Workshop on Computing
Within Limits. ACM, Santa Barbara California USA, 59-70. https://doi.org/10. $1145 / 3080556.3080563$ 